NBER WORKING PAPER SERIES

\title{
RACIAL/ETHNIC DIFFERENCES IN NON-WORK AT WORK
}

\author{
Daniel S. Hamermesh \\ Katie R. Genadek \\ Michael Burda \\ Working Paper 23096 \\ http://www.nber.org/papers/w23096 \\ NATIONAL BUREAU OF ECONOMIC RESEARCH \\ 1050 Massachusetts Avenue \\ Cambridge, MA 02138 \\ January 2017
}

Hamermesh thanks the Alexander von Humboldt Stiftung for general financial support; Genadek was supported by the University of Colorado Population Center (HD066613), the Minnesota Population Center at the University of Minnesota (HD041023) and the Data Extract Builder of the ATUS (University of Maryland, HD053654), all funded by NICHD; Burda received general support from the Collaborative Research Center 649 "Economic Risk" of the Deutsche Forschungsgemeinschaft. None of these institutions provided funding for this project directly, nor did any other institution. The content is solely the responsibility of the authors and does not necessarily represent the official views of the institutions. We thank Kevin Carney, Christopher Gallo, Joanne Kleydish, Anna Maria Koukal, Michael Naef and participants in seminars at several universities for helpful comments. The views expressed herein are those of the authors and do not necessarily reflect the views of the National Bureau of Economic Research.

NBER working papers are circulated for discussion and comment purposes. They have not been peer-reviewed or been subject to the review by the NBER Board of Directors that accompanies official NBER publications.

(C) 2017 by Daniel S. Hamermesh, Katie R. Genadek, and Michael Burda. All rights reserved. Short sections of text, not to exceed two paragraphs, may be quoted without explicit permission provided that full credit, including $(\odot$ notice, is given to the source. 
Racial/Ethnic Differences in Non-Work at Work

Daniel S. Hamermesh, Katie R. Genadek, and Michael Burda

NBER Working Paper No. 23096

January 2017

JEL No. J15,J22,J31

\begin{abstract}
$\underline{\text { ABSTRACT }}$
Evidence from the American Time Use Survey 2003-12 suggests the existence of small but statistically significant racial/ethnic differences in time spent not working at the workplace. Minorities, especially men, spend a greater fraction of their workdays not working than do white non-Hispanics. These differences are robust to the inclusion of large numbers of demographic, industry, occupation, time and geographic controls. They do not vary by union status, publicprivate sector attachment, pay method or age; nor do they arise from the effects of equalemployment enforcement or geographic differences in racial/ethnic representation. The findings imply that measures of the adjusted wage disadvantages of minority employees are overstated by about 10 percent.

Daniel S. Hamermesh

Department of Economics

Royal Holloway University of London

Egham, TW20 0EX

UNITED KINGDOM

and NBER

Daniel.Hamermesh@rhul.ac.uk

Michael Burda

Faculty of Business and Economics

Humboldt University Berlin

Spandauer Str. 1

D-10178 Berlin

Germany

burda@wiwi.hu-berlin.de

Katie R. Genadek

University of Colorado

Boulder, CO 80839

kgenadek@umn.edu
\end{abstract}




\section{Hours on the Job and Hours Working}

Commonly used statistics on labor productivity and real wages are normally computed by dividing measures such as earnings by hours reported as having been worked. Estimates of (adjusted) wage differentials (discrimination) across racial-ethnic-gender groups require adjusting weekly earnings for differences in hours worked among these groups. In the United States the commonly used measures of hours are either reported weekly hours in the monthly household-based Current Population Survey (CPS), weekly, monthly or annual hours in other household surveys, or weekly hours reported by employers in the monthly Current Employment Statistics (CES).

The use of any of these measures may produce biased estimates of the outcomes of interest, including time series of changes in labor productivity (examined by Burda et al, 2013 and 2016), measures of growth in living standards per hour of work, and demographic wage differentials in the cross section. If, for example, reported hours exceed actual hours worked by less among minority and/or female workers than among others, estimates of adjusted hourly wage/earnings differentials will understate the extent of discriminatory differences in earnings.

Until recently accounting for this potential difficulty was not possible-no nationally representative data set provided information on what people do during the hours that they report working. The American Time Use Survey (ATUS) (see Hamermesh et al, 2005) provides diary information on over 400 possible activities engaged in by large samples of (former CPS) respondents, including detailed information on a wide variety of different activities undertaken in the workplace. We use these data from 2003-12 to examine differences among demographic groups in the amount of time that they spend at the workplace but not working (Hofferth et al, 2015). 


\section{ATUS Measures of Time Use on the Job}

As part of its daily diaries, the ATUS includes information on where during each of most of the activities that were undertaken the respondent was located, with one possibility being "at the workplace." Work and work-related activities (including socializing, and eating and exercising as a part of the job) constitute the primary activity for most time at the workplace, and we assume it represents productive time; but respondents also indicate being at the workplace during other primary activities such as eating at work, "socializing, relaxing and leisure," "sports and exercise" and "security procedures". These categories also include employer-sanctioned breaks or self-initiated "down time" in work schedules. We combine all time spent in primary activities at work other than work or work-related activities and divide by reported (in the diary) total time at the workplace to create $\eta$, the fraction of time while at the workplace that the person is not working. This measure excludes time when the person might be working for pay but is not at the workplace. One might regard some of these non-work activities as productive, as are many offthe-job activities (e.g., exercise, sleep and many others); but we accept respondents' notions of what constitutes their regular work, as reflected in their diaries, and treat the residual time at work as non-work.

The first decade of ATUS diaries, 2003-12, included over 135,000 respondents. Because we require diaries from workdays, and because the ATUS oversamples weekend days, far fewer diaries are usable for our purpose. Moreover, since our estimates can form the basis for adjusting wage differentials, worker productivity, and other outcomes, we focus only on employees (thus excluding the self-employed). These exclusions leave us with 35,548 workers who provided daily diaries for days on which they were at their place of employment. We divide the sample by gender, then divide workers in each gender into five mutually exclusive and exhaustive 
racial/ethnic groups: Non-Hispanic white; African-American; Non-black Hispanic; AsianAmerican, and Other. We classify any Non-black respondent listing his/her ethnicity as Hispanic in the third category.

In Table 1 we present estimates of $\eta$, the fraction of the workday not working, by gender and racial/ethnic group, constructed as means using BLS ATUS final weights. There are substantial differences in the $\eta$ within each gender across the racial ethnic groups, with Non-Hispanic whites reporting less non-work time per hour at work than other groups. Of course, these differences do not account for demographic or other differences across the groups, and we explore those in the next section.

A notable feature in these statistics is that $\eta$ is nearly identical between Non-Hispanic white men and women. For workers of each gender about 6.5 percent of time at the workplace is spent not working—about a half hour in a full work day. ${ }^{1}$ Among minority groups there is no obvious general pattern of differences between male and female workers-African-American, Non-black Hispanic and Other men spend greater fractions of their time in non-work activities than their female counterparts, while Asian-American male workers spend less.

One might be concerned that the samples are unrepresentative in various ways, perhaps due to the exclusion restrictions that we have used in creating this sub-sample. This concern should be allayed, at least for male workers, by comparisons within columns of the fourth and fifth rows in the upper half of Table 1. The weighted fractions of male workers in each of the five racial/ethnic groups are very near those reported in the American Community Survey (ACS) averaged over 2003-2012 (Ruggles et al, 2015). The differences between female workers' representation in our ATUS sub-sample and the ACS are proportionately larger than the

\footnotetext{
${ }^{1}$ Remember that time eating during work hours is usually not at the workplace, which accounts for what might seem like a small fraction of worktime spent not working on the job.
} 
differences among men; but they are fairly small absolutely among the three largest racial/ethnic groups.

\section{Accounting for Other Demographic, Industry and Occupational Influences}

The raw differences shown in the top rows of each half of Table 1 are interesting but not conclusive, because they could stem from differences in the amount of time spent at the workplace or in the number of hours usually worked; from racial/ethnic differences in labor supply due to family circumstances; from demand-side differences arising from differential occupation/industry attachment by race/ethnicity; and perhaps even from differences in location, or in the day of the week or month of the year for which the time diary is completed. In what follows, we estimate OLS regressions for $\eta$ to account for the roles played by these factors, adding increasingly large numbers of vectors of covariates. We use Non-Hispanic whites within each gender as the comparison group and examine how the addition of these covariates alters our conclusions about racial/ethnic relative differences in non-work time at work.

The first rows in the top and bottom parts of Table 2 present the differences in $\eta$ between workers in each of the four racial/ethnic minorities and that of Non-Hispanic whites, simply reproducing the differences implicit in Table 1, plus adding their standard errors. They are thus estimates of $\alpha_{1}$ in the equation:

(1) $\eta_{\text {ist }}=\alpha_{0}+\alpha_{1} X_{\text {ist }}+\varepsilon_{\text {ist }}$,

where $\mathrm{i}$ is an individual, $\mathrm{s}$ a state, $\mathrm{t}$ a month, $\mathrm{X}$ is the vector of indicators of race/ethnicity, the $\alpha$ are parameters to be estimated, and $\varepsilon$ is the disturbance term. What is most intriguing in these raw differences is that all four are positive - all the minorities that are identifiable in the CPS, including those that may be viewed as not being disadvantaged, spend greater fractions of their time at work not working when compared to non-Hispanic whites. They are largest, and 
statistically greater than zero, for the two largest minority groups, African-Americans and Nonblack Hispanics. In the second rows of each half of the table we simply add pairs of quadratics in the length of the respondent's usual workweek, as recalled, and the time spent at the workplace on the diary day, as recorded in the diary. These controls hardly alter the racial/ethnic differences in $\eta$, suggesting if anything that the raw differences are understatements.

Because race and ethnicity are correlated with such demographic differences as marital status, age and number of children, geography and others, the differentials in the second rows of Table 2 may merely be reflecting familial and other incentives that alter the amount of non-work on-the-job. To account for this possibility, the third rows include as covariates: Marital and metropolitan status; a quadratic in potential experience; vectors of five indicators of the ages of the children in the household, and four indicators of the respondent's educational attainment.

Except for Asian-Americans, the inclusion of these covariates does reduce the estimated differential in reported non-work time between minority groups and majority workers. The differences remain statistically significant for the two largest groups, however, and they become statistically significant among Asian-American workers. The greater propensity for on-the-job non-work noted in Table 1 is not due to differences in demographic characteristics between minority and majority workers.

The estimates thus far do not account for the possibility that the structure of labor demand by race/ethnicity differs across industries and occupations; nor do they acknowledge, even with workdays of the same length, that the extent of non-work may differ by day of week or time of year; nor do they recognize that other characteristics may differ geographically. To account for these possibilities we re-estimate the equations adding vectors of indicators of the month of the 
year and day of the week on which the diary was kept; of geographic area (state); and of what are essentially two-digit classifications of occupation and industry.

The results of adding these additional controls are shown in the fourth rows of Table 2 . Among men all of the estimated racial/ethnic differences in non-work decline, but for NonHispanic black, Non-black Hispanic, and Asian-American men the significantly positive results of the previous estimates persist; and the reductions of the differentials for the two largest minority groups are quite small. Among female workers the reductions in the estimated effects are large, but here too they remain statistically significant and positive for workers in the two largest minority groups.

We can go further by replacing the vectors of two-digit occupation and industry indicators by much longer vectors, accounting for over 500 occupations and over 250 industries. The results of making these substitutions are presented in the bottom rows of the two parts of Table 2. Among men including these much finer controls does reduce the estimated minority-majority differentials in $\eta$; but those differentials that had been significantly positive remain so. Among women workers including these additional covariates also reduces the estimated racial/ethnic differentials, but the changes are small compared to the estimates based on including the broader industry/occupation indicators. ${ }^{2}$

Do the differentials arise from a greater willingness of minorities to report non-work time on the job or from cultural differences about what constitutes actual work? First, that all minorities report more non-work would, if it stemmed from cultural differences, imply similar attitudes

\footnotetext{
${ }^{2}$ If we re-estimate these final equations dropping time spent eating at the workplace, the racial-ethnic differentials for male workers are proportionately even larger, while those for female workers are approximately the same. If we include both the quadratic in time at the workplace from the time diaries and total time reported in the diaries as working, the adjusted demographic differences are essentially unchanged. While all of the estimates reported in the tables and discussed in the text use the proportions of time at work spent not working, using the raw amounts of non-work time instead yields slightly larger and more statistically significant racial/ethnic differentials.
} 
across the minority groups, which seems hard to credit. Second, if cultural differences between minority groups and the majority workers are causing reporting differences, one would expect that they would be greater among immigrant minority workers, who have had less time to assimilate to the majority culture. Interactions of immigrant status with the race/ethnic indicators are, however, far from statistically significant when added to the specifications in the bottom rows of Table 2. Third, the findings do not stem from minorities' greater willingness to report different activities, including non-work on the job. Non-Hispanic whites report 19.78 $(\mathrm{s} . \mathrm{e} .=0.032)$ different activities per day on average, while the average numbers of different activities reported by minorities are: African-Americans, 18.77 (s.e. $=0.078)$, Non-black Hispanics, 18.05 (s.e. $=0.071)$, Asian-Americans 18.90 (s.e. $=0.134)$, Others, 19.63 (s.e. $=0.188)$. Minorities report fewer different activities per day than otherwise identical majority workers.

The best evidence that these results do not merely arise from differing willingness to report non-work due to racial differences in the social desirability of work comes from analyses of the General Social Surveys. They have included two questions that allow examining such differences: 1) For all respondents, "If you were to get enough money to live as comfortably as you would like for the rest of your life, would you continue to work or would you stop working?" and 2) For workers, agreement with the statement, "My main satisfaction in life comes from work." Estimating a probit (ordered probit) on the responses to Question 1 (2) and excluding racial groups other than whites and African-Americans, the latter are insignificantly more likely to say they would stop work; but they are nearly significantly more likely to agree or agree strongly with the statement about the importance of satisfaction with work. (See Appendix Table A1 for results.) There is clearly no racial difference in how people view the desirability of 
work, suggesting (but not proving) that differences in willingness to report non-work at work are unimportant.

A number of institutional differences among the sample observations might account for or at least minimize the findings implied in the bottom rows of the panels in Table 2. Trade unions may provide more services to minority workers, perhaps for political reasons (at least to AfricanAmerican workers, who are more heavily unionized than other groups), perhaps arising from preferences of union members and leaders to protect minority workers. To examine this possibility we added an indicator of union status and its interactions with the four racial/ethnic indicators. Among men (women) the F-statistic on the significance of these interactions yielded $\mathrm{p}=0.82(\mathrm{p}=0.41)$, suggesting that these racial/ethnic differences in non-work arise in both union and non-union environments.

Hourly workers may be monitored more closely, and this might account for racial/ethnic differentials in non-work. We added an indicator of hourly pay status and its interactions with the racial/ethnic indicators to the expanded equations shown in the bottom rows of Table 2. Among women the F-statistic on the interactions yielded $p=0.30$, but among men the vector of interactions was statistically significant $(\mathrm{p}=0.04)$. Its significance was, however, due entirely to the significance of the interaction with the indicator for Asian-Americans. In a similar set of expanded specifications distinguishing between the roughly one-sixth of workers in the public sector and others there was again no significant difference in the racial/ethnic non-work differentials by sector, with the F-statistic on the interaction terms for men (women) yielding $\mathrm{p}=$ $0.88(\mathrm{p}=0.12)$.

Finally, the influence of age on non-work time may differ between majority and minority workers. To examine this, we created an indicator, age $\leq 40$, which divided the samples 
essentially in halves. Including this indicator and its interactions in the expanded equations shown in Table 2, we found no difference in the racial/ethnic non-work differentials by age: Among men (women) the significance of the F-statistics describing the four interaction terms was $p=0.33(p=0.36)$. All four re-specifications described in these paragraphs support the robustness of the results presented in the bottom rows of each panel of Table 2 across various cuts of the data.

While the descriptive statistics in Table 1 allow comparisons by racial/ethnic group of gender differences in non-work, they do not account for differences that might arise from any malefemale differences in the large sets of controls that we added to generate most of the estimates in Table 2. To obtain an adjusted gender difference in on-the-job non-work we estimate the equation in the last rows of Table 2 for all 35,548 workers in the sample. All these other things equal, male workers spend an additional fraction of 0.001 (s.e. $=0.002)$ of the workday not working compared to female workers. The conclusion of little gender difference conveyed by the raw differences in Table 1 is supported even after accounting for large numbers of possible covariates. While there are significant racial/ethnic differentials in non-work on the job, there is essentially no difference between otherwise identical male and female employees.

Aggregating the adjusted effects among men, the best estimate is that on average minority male workers (based on a sample-weighted average of the parameter estimates in the bottom row of the top half of Table 2) spend an additional 1.10 percent of each workday not working on-thejob compared to their majority counterparts. Over a 250-day full-time work year this amounts to an additional 22 hours per year of not working while at work. Taking all four female minority groups together, these best estimates suggest that the average minority female worker spends 
0.64 percent less of each additional hour at work actually working compared to her majority counterparts, i.e., 14 hours of a full-time work year. ${ }^{3}$

\section{The Economic Significance of Racial-Ethnic Differences in Non-Work and Their Cause(s)}

\section{A. The Economic Magnitude of the Differences in Non-Work}

While statistically significant and robustly so, these racial/ethnic differences are not large. To what extent do these results alter our conclusions about the extent of racial/ethnic differences in outcomes, in particular in hourly earnings - the best measure of the price of labor of different races/ethnicities? How do they compare to the impacts of various shocks to other outcomes of interest generated in the literatures in labor and demographic economics?

On the first issue, a recent study (Anant et al, 2013) estimated adjusted black-white wage differentials at around 14 percent, Hispanic- non-Hispanic white adjusted wage differentials at around 15 percent, Asian-American wage differences at around 13 percent, and white-Other differences at around 14 percent. D'Haultfoeuille et al (2014) find median estimates of the black-white wage gap using samples from the NLSY79 and NLSY97 of around 12 percent. Thus using our estimates for men, and adjusting reported hours worked for racial/ethnic differences in on-the-job non-work, the measured extent of discrimination against African-Americans would be reduced by more than 1 percentage point (about a 10 percent reduction), and among AfricanAmerican women by over one-half percentage point. In comparison, these are no smaller than the adjustments/explanations that have been produced in studies that have examined the impacts of unusual determinants of demographic differences in wages (e.g., Gielen et al, 2016).

\footnotetext{
${ }^{3}$ One might argue that the differences that we have identified arise because of racial/ethnic differences in time use away from the job. Minorities might spend more time commuting, might sleep less or might engage in more household production. These measures may well be endogenous with non-work time at work; nonetheless, to examine their relation to the racial/ethnic differences we have focused on, we include each separately in the expanded equations shown in the bottom of each panel of Table 2, then include them jointly. Including each separately actually raises slightly the estimated excess of minority over majority non-work time. Taking them together, their inclusion raises the excess among men (women) by about 10 (15) percent.
} 
It is more difficult to compare the magnitudes of the impacts of the adjusted racial/ethnic differences in on-the-job non-work to the impacts of shocks in other areas where there is no monetary outcome to consider. Thus the best comparisons use differences measured in standarddeviation units. Among men (women) the adjusted weighted average estimated differences in non-work between minority and majority workers are $0.10(0.06)$ of a standard deviation. These are much greater than some produced in the demographic literature (e.g., Banerjee et al, 2010) and comparable to the larger effects on educational outcomes (test scores) of variations in teacher quality found in the education literature (e.g., Rivkin et al, 2005).

\section{B. Sorting Out Possible Causes}

Merely demonstrating the existence of significant differences in on-the-job non-work between minority and majority workers does not establish their origins. In what follows, we first examine several mechanisms by which incentives might generate the differentials that we have identified: 1) Perhaps differential access to anti-discrimination protection leads minority workers to alter their non-work in the workplace; 2) Perhaps having more similar workers in the workplace and in the community alters the extent of non-work; 3) Yet a third possibility is that, perceiving that discrimination reduces their chances for promotion, minority employees reduce their effort at work

Before examining these alternatives we should note that, although we have held constant for remarkably detailed industry and occupation characteristics, even within those narrow cells minorities may be assigned to tasks that are inherently more strenuous and require more "down time." Clearly, with these data we cannot investigate this explanation. Still another alternative is that the extra non-work time experienced by minority employees enables them to be more productive than majority employees during the (lesser) amount of time per hour on the job that 
they are actually working (consistent with some older, loosely related indirect evidence-(Hellerstein et al, 1999).

Greater protection by more stringent enforcement of equal-employment legislation might reduce the firing risk perceived by minority workers if caught not working at work. One would thus expect that interactions of the strength of enforcement of EEO legislation in the labor market where a worker resides with the indicators $\mathrm{X}$ in (1) would yield positive estimates, since additional EEO charges would suggest that minority workers have more protection should they engage in more non-work activities on the job. To examine this possibility we collected information on EEOC filings by state for the available years (2009-12) (EEOC, 2015); for the earlier years, 2003-08, we impute the average for 2009-12 in the state of the worker's residence. In the extension of (1) we include EEOC charges per year per thousand employees in the state and year as a main effect and in interactions with the vector $\mathrm{X}$. The mean of the EEO measure is 0.75 (s.d. $=0.39)$, and it ranges between 0.01 and 2.08 .

We present the results of including this term and the interactions for men and for women in the upper two rows of the top and bottom halves of Table 3. Each equation also includes the nearly 1000 covariates that were included in the estimates shown in the bottom rows of Table 2 . The standard errors are clustered on the EEOC charges variable.

Other things equal, workers of all races/ethnicities (especially men) do spend greater fractions of the workday not working in states in which more EEOC charges are filed. Among men three of the four interaction terms are not, however, significantly different from zero; but because the interaction is statistically significant among Non-black Hispanics, an F-test of the joint significance of the vector of four interactions rejects the hypothesis that they are zero. Three of the four are, however, negative, contrary to our expectations that greater EEO enforcement 
would raise incentives for non-work by minority workers. Among women the interactions are also negative (again with the exception of the Other minority category), but none is statistically significant individually, and the F-statistic testing the significance of the vector of interactions is tiny. Taking all these results together, a reasonable conclusion is that the extent of EEOC enforcement in an area does not appear to alter the on-the-job non-work behavior of minority compared to majority workers.

The second possible explanation based on incentives is that the representation of a minority group in an area might alter workers' incentives for non-work and employers' interest in monitoring workers. If minority workers in an area are more numerous, they may feel protected from firing or may feel peer pressure to work less on the job (Mathewson, 1931). On the other hand, employers' greater willingness to monitor minority workers where they are more visible is consistent with the taste theory of discrimination (Becker, 1957) and would lead to less nonwork by minorities. To examine these ideas we include the percentages of employees in each minority group (based on total ACS employment in the state and year) and their interactions with the worker's racial/ethnic indicator in expanded versions of the final equations in Table 2 . The means of the four racial/ethnic average fractions of male workers are: African-American, 0.096 (s.d.=0.065); Non-black Hispanic, 0.145 (s.d.=0.121); Asian-American, 0.044 (s.d.=0.040); and Other groups, $0.021(0.016){ }^{4}$

The estimates of the interactions in these expanded equations are shown in the third row in each of the two panels in Table 3, with the significance of the F-statistic testing the four interaction terms also shown. Only one of the interaction terms is statistically significantly nonzero (again, among Non-black Hispanic men); and the interactions as groups are far from

\footnotetext{
${ }^{4}$ Among women the comparable statistics are: African-Americans, 0.127 (s.d. $=0.087$ ); Non-black Hispanics, 0.117 (s.d. $=0.107$ ); Asian-Americans, 0.045 (s.d. $=0.047$ ); other groups, 0.023 (s.d. $=0.019$ ).
} 
statistically significantly nonzero. Moreover, even across the wide variation in the percentage representations of minorities in different labor markets there is little impact on the amount of non-work at work by minorities in the labor market. Perhaps the two opposite effects noted above offset each other, or perhaps they just do not matter. Regardless, these tests make clear that on net the importance of a racial/ethnic group in a labor market does not affect its members' non-work time on the job.

A third possibility is that minorities spend more time not working on the job since discriminatory promotion practices lower the returns to effort - especially regarding promotion and long-term career prospects - and thus the long-term penalties for non-work. If this explanation were correct, we would expect that self-employed minority workers would not differ in their non-work on the job from majority self-employed workers. To examine this possibility we re-estimated the equations at the bottom of the two panels of Table 2 over self-employed workers, collapsing the indicators of minority status into one because of the relative paucity of minority self-employed workers in the samples (only 504 minority men, 204 minority women).

We saw that the aggregate of minority male (female) employees spends $1.10(0.64)$ percent of the work-day more in non-work on the job than does the aggregate of majority male employees. Among self-employed males (females), minority workers spend 1.2 (1.2) percent of the work-day more in non-work than do majority self-employed workers. Because of the relatively small samples of self-employed minority workers, the estimated relative differences between majority and minority employed and self-employed workers are not statistically nonzero. The point, estimates, however, suggest that there is no difference in the relative amounts of non-work, implying that discrimination in promotion opportunities for minority employees is not generating our results. 
Perhaps minority employees exert less effort per hour on the job because their lives are more stressful and the reduced effort at work compensates for their extra stress. We can examine this possibility using two data sets. First, in 2003 the PSID included a question asking one respondent per household, "How often do you feel rushed or pressed for time? Almost always; often; sometimes; rarely; never." (See Hamermesh and Lee, 2007). Other things equal, AfricanAmerican men are less likely to say that they are almost always or often stressed for time than are other men, but the difference between them and whites is not quite statistically significant. African-American women are significantly less likely to feel stressed for time than otherwise identical women.

Second, in several years the ATUS asked respondents to indicate how stressed they were while performing a particular activity at three randomly chosen times of the diary day, with responses ranging from 0 indicating no stress to 6 indicating the respondent felt very stressed during that activity. We estimate activity-level ordered probits over this measure. The estimates suggest that, other things equal, African-Americans are significantly less likely to state that they were stressed during randomly selected activities. The differences for Non-black Hispanics and Asian-Americans are small and negative, with t-statistics below one, while that for Others is positive and nearly significant statistically. These results from the PSID and the ATUS counter the notion that lesser on-the-job effort by minorities is a response to general feelings of stress. ${ }^{5}$

Finally, yet an additional explanation is that these demographic differences arise from differences in preferences of workers in different racial/ethnic groups. Obviously we cannot test this notion on the available data. It is, however, consistent with cultural differences in which

\footnotetext{
${ }^{5}$ These ATUS results and the PSID estimates discussed in the preceding paragraph are presented in Appendix Table A2.
} 
minorities are generally less stressed than similarity members of the majority group, a cultural difference that leads them to be more relaxed about effort on the job.

\section{Conclusions}

We have demonstrated that minorities in the United States-African-Americans, Non-black Hispanics, Asian-Americans and others - on average spend larger fractions of their time at work engaged in non-work activities than do majority workers. These differences are robust to the inclusion of large numbers of demographic variables, measures of work time and even extremely detailed indicators of industry and occupational attachment. They are, moreover, not tiny-they are large enough to suggest some modifications of our notions of the magnitudes of racial/ethnic differences in pay per hour of effort, leading perhaps to reductions of 10 percent in the estimated earnings/effort disadvantage of African-American and Hispanic men.

We rejected a large range of explanations for the differences in effort based on incentives at work facing minorities. Similarly, they are not explained by differences in the amounts and kinds of activities undertaken outside the workplace. Rather, they are consistent with cultural differences that lead minorities to be more relaxed about life, including life in the workplace, than are non-minority workers, and to be more willing to mix non-work with work.

The ATUS is the only nationally representative data set of which we are aware that provides information on what large samples of workers are engaged in while at work. This uniqueness is unfortunate - the questions that might be answered with more such data go well beyond pointing out demographic differences in effort at work (although these differences are important for such labor-market outcomes as worker productivity and wage differentials). Expanded information on time use at work would enable much deeper study of the temporal dynamics of worker 
productivity, putting the scientific management studies of the post-World War I era (e.g., Florence, 1924) on a much more general and more broadly applicable basis. 


\section{REFERENCES}

Elizabeth Ananat, Shihe Fu and Stephen Ross, "Race-Specific Agglomeration Economics; Social Distance and the Black-White Wage Gap,” NBER Working Paper No. 18933, 2013.

Abhijit Banerjee, Esther Duflo, Gilles Postel-Vinay and Tim Watts, "Long Run Health Impacts of Income Shocks: Wine and Phylloxera in $19^{\text {th }}$ Century France," Review of Economics and Statistics, 92 (Nov. 2010): 714-28.

Gary Becker, The Economics of Discrimination. Chicago: University of Chicago Press, 1957.

Michael Burda, Katie Genadek and Daniel Hamermesh, "Not Working at Work: Loafing, Unemployment and Labor Productivity," NBER Working Paper No. 21923, Jan. 2016.

Michael Burda, Daniel Hamermesh and Jay Stewart, "Cyclical Variation in Labor Hours and Productivity Using the ATUS," American Economic Association: Papers \& Proceedings, 103 (May 2013): 99104.

P. Sargant Florence, Economics of Fatigue and Unrest. New York: Henry Holt, 1924.

Anne Gielen, Jessica Holmes and Caitlin Myers, "Testosterone and the Earnings of Men and Women," Journal of Human Resources, 51 (Winter 2016): 30-61.

Daniel Hamermesh and Jungmin Lee. "Stressed Out on Four Continents: Time Crunch or Yuppie Kvetch?" Review of Economics and Statistics, 89 (May 2007): 374-83.

Daniel Hamermesh, Harley Frazis and Jay Stewart, "Data Watch: The American Time Use Survey," Journal of Economic Perspectives, 19 (Winter 2005): 221-32.

Xavier D'Haultfoeuille, Arnaud Maurel and Yichong Zhang, "Extremal Quantile Regressions for Selection Models and the Black-White Wage Gap," NBER Working Paper No. 20257, 2014.

Judith Hellerstein, David Neumark and Kenneth Troske, "Wages, Productivity and Worker Characteristics: Evidence from Plant-Level Production Functions and Wage Equations," Journal of Labor Economics, 17 (July 1999): 409-46.

Sandra L. Hofferth, Sarah M. Flood, and Matthew Sobek. 2015. American Time Use Survey Data Extract System: Version 2.5 [Machine-readable database]. Maryland Population Research Center, University of Maryland, College Park, Maryland, and Minnesota Population Center, University of Minnesota, Minneapolis, Minnesota.

Stanley Mathewson, The Restriction of Output Among Unorganized Workers. New York: Viking, 1931.

Steven Rivkin, Eric Hanushek and John Kain, "Teachers, Schools, and Academic Achievement," Econometrica, 73 (March 2005): 417-58.

Steven Ruggles, Katie Genadek, Ronald Goeken, Josiah Grover, and Matthew Sobek. Integrated Public Use Microdata Series: Version 6.0 [Machine-readable database]. Minneapolis: University of Minnesota, 2015.

U.S. Equal Opportunity Commission, FY 2009 - 2014 EEOC Charge Receipts by State (includes U.S. Territories) and Basis. Washington: EEOC, 2015. https://www1.eeoc.gov/eeoc/statistics/enforcement/charges_by_state.cfm 
Table 1. Non-work Time at Work and Ethnic Representation, ATUS Employees, 2003-12*

$\begin{array}{ccc}\begin{array}{c}\text { Non-Hispanic } \\ \text { White }\end{array} & \begin{array}{c}\text { African- Non-black } \\ \text { American Hispanic American }\end{array} & \text { Other } \\ & \text { MEN }(\mathrm{N}=17,777)\end{array}$

$\begin{array}{lccccc}\text { Fraction of Time Not Working } & 0.0645 & 0.0793 & 0.0848 & 0.0679 & 0.0701 \\ & (0.0022) & (0.0063) & (0.0055) & (0.0099) & (0.0133) \\ \mathrm{N}= & 12,348 & 1830 & 2582 & 651 & 366 \\ \text { ATUS Sample Ethnic Mean } & 0.695 & 0.103 & 0.145 & 0.037 & 0.021 \\ \text { ACS Ethnic Mean } & 0.693 & 0.096 & 0.1454 & 0.044 & 0.021 \\ & & & & \\ & & \text { WOMEN }(\mathbf{N}=\mathbf{1 7 , 7 7 1}) & & \\ \text { Fraction of Time Not Working } & 0.0646 & 0.0758 & 0.0779 & 0.0724 & 0.0649 \\ & (0.0023) & (0.050) & (0.0058) & (0.105) & (0.129) \\ \text { N = } & 11,877 & 2787 & 2137 & 605 & 365 \\ \text { ATUS Sample Ethnic Mean } & 0.668 & 0.156 & 0.120 & 0.034 & 0.021 \\ \text { ACS Ethnic Means } & 0.687 & 0.127 & 0.118 & 0.046 & 0.023\end{array}$

*Standard errors in parentheses here and in Tables 2 and 3. 
Table 2. Parameter Estimates, Racial/Ethnic Effects on the Fraction of Worktime Not Working, ATUS Employees, 2003-12 (with Non-Hispanic Whites as the Base Group)*

\section{African- Non-black Asian- Other American Hispanic American}

\section{Equation}

\begin{tabular}{|c|c|c|c|c|}
\hline \multirow{3}{*}{ Raw } & \multicolumn{3}{|c|}{ MEN } & \multirow{3}{*}{$\begin{array}{l}0.0056 \\
(0.0059)\end{array}$} \\
\hline & 0.0148 & 0.0203 & 0.0034 & \\
\hline & $(0.0036)$ & $(0.0031)$ & $(0.0036)$ & \\
\hline \multirow{2}{*}{$\begin{array}{l}\text { Add workday, workweek } \\
\text { quadratics }\end{array}$} & 0.0144 & 0.0226 & 0.0063 & 0.0080 \\
\hline & $(0.0035)$ & $(0.0030)$ & $(0.0036)$ & $(0.0062)$ \\
\hline \multirow[t]{2}{*}{ Add demographics** } & 0.0128 & 0.0194 & 0.0123 & 0.0072 \\
\hline & $(0.0035)$ & $(0.0031)$ & $(0.0036)$ & $(0.0061)$ \\
\hline \multirow{2}{*}{$\begin{array}{l}\text { Add industry, occupation, } \\
\text { state, month, day of week } \\
\text { indicators } * * *\end{array}$} & 0.0119 & 0.0171 & 0.0089 & 0.0070 \\
\hline & $(0.0037)$ & $(0.0034)$ & $(0.0039)$ & $(0.0065)$ \\
\hline \multirow{2}{*}{$\begin{array}{l}\text { Add very detailed industry, } \\
\text { occupation indicators } * * * *\end{array}$} & 0.0082 & 0.0153 & 0.0087 & 0.0030 \\
\hline & $(0.0038)$ & $(0.0034)$ & $(0.0040)$ & $(0.0062)$ \\
\hline \multirow{3}{*}{ Raw } & & WOME & & \\
\hline & 0.0112 & 0.0132 & 0.0078 & 0.0025 \\
\hline & $(0.0027)$ & $(0.0034)$ & $(0.0057)$ & $(0.0063)$ \\
\hline \multirow{2}{*}{$\begin{array}{l}\text { Add workday, workweek } \\
\text { Quadratics }\end{array}$} & 0.0125 & 0.0149 & 0.0092 & -0.0009 \\
\hline & $(0.0027)$ & $(0.0033)$ & $(0.0059)$ & $(0.0064)$ \\
\hline \multirow[t]{2}{*}{ Add demographics** } & 0.0113 & 0.0113 & 0.0120 & -0.0026 \\
\hline & $(0.0027)$ & $(0.0034)$ & $(0.0059)$ & $(0.0064)$ \\
\hline \multirow{2}{*}{$\begin{array}{l}\text { Add industry, occupation, } \\
\text { state, month, day of week } \\
\text { indicators } * * *\end{array}$} & 0.0094 & 0.0077 & 0.0081 & -0.0037 \\
\hline & $(0.0031)$ & $(0.0039)$ & $(0.0064)$ & $(0.0066)$ \\
\hline \multirow{2}{*}{$\begin{array}{l}\text { Add very detailed industry, } \\
\text { occupation indicators } * * * *\end{array}$} & 0.0086 & 0.0062 & 0.0057 & -0.0045 \\
\hline & $(0.0031)$ & $(0.0039)$ & $(0.0067)$ & $(0.0070)$ \\
\hline
\end{tabular}


Table 3. Parameter Estimates, Experiments with EEO Charges and Union Coverage, ATUS Employees, 2003-12 (Racial-Ethnic Effects with Non-Hispanic Whites as the Base Group, Mean EEO Charges $=0.764 / 1000$ Employees)

$\begin{array}{cccc}\text { African- } & \text { Non-black } & \text { Asian- } & \text { Other } \\ \text { American } & \text { Hispanic } & \text { American }\end{array}$

Equation Main Effect

\begin{tabular}{|c|c|c|c|c|c|}
\hline \multirow{3}{*}{$\begin{array}{l}\text { EEO Charges per } \\
\text { Employee: Own Effect }\end{array}$} & \multicolumn{5}{|c|}{ MEN } \\
\hline & 0.0403 & 0.0119 & 0.0344 & 0.0165 & -0.0048 \\
\hline & $(0.0244)$ & $(0.0101)$ & $(0.0078)$ & $(0.0080)$ & $(0.0099)$ \\
\hline F-stat. p, and Interactions: & 0.029 & $\begin{array}{r}-0.0044 \\
(0.0093)\end{array}$ & $\begin{array}{c}-0.0255 \\
(0.0086)\end{array}$ & $\begin{array}{c}-0.0110 \\
(0.0104)\end{array}$ & $\begin{array}{l}0.0106 \\
(0.0134)\end{array}$ \\
\hline \multicolumn{2}{|l|}{ Interactions with Racial/Ethnic } & 0.0072 & -0.1025 & 0.0385 & 0.0524 \\
\hline \multirow[t]{2}{*}{ Fractions, F-stat. $\mathrm{p}$} & 0.374 & $(0.0444)$ & $(0.0530)$ & $(0.0546)$ & $(0.1398)$ \\
\hline & \multicolumn{5}{|c|}{ WOMEN } \\
\hline EEO Charges per & 0.0183 & 0.0139 & 0.0131 & 0.0001 & 0.0057 \\
\hline Employee: Own Effect & $(0.0299)$ & $(0.0079)$ & $(0.0085)$ & $(0.01115)$ & $(0.0146)$ \\
\hline \multirow[t]{2}{*}{ F-stat. p, and Interactions } & 0.712 & -0.0058 & -0.0091 & 0.0083 & -0.0131 \\
\hline & & $(0.0088)$ & $(0.0103)$ & $(0.0207)$ & $(0.0159)$ \\
\hline \multicolumn{2}{|l|}{ Interactions with Racial/Ethnic } & -0.0064 & -0.0100 & -0.0570 & 0.0265 \\
\hline Fractions, F-stat. $\mathrm{p}$ & 0.889 & $(0.0340)$ & $(0.0453)$ & $(0.0614)$ & $(0.1516)$ \\
\hline
\end{tabular}

*All equations include a vector of education indicators; a quadratic in potential experience; a vector of indicators of the age of the youngest child; indicators of metro and marital status; and vectors of indicators for 513 occupations, 259 industries, 51 States and 6 days of the week. 


\section{Appendix Table A1. Racial Effects on Attitudes Toward Work (Parameter Estimates on Indicator for African-American), GSS Various Waves*}

\section{Dep. Var.:}

\section{Would continue to work if rich**}

$\mathrm{N}=$

Work is main source of satisfaction***

$\mathrm{N}=$

*Standard errors in parentheses below the parameter estimates here and in Appendix Table A2.

**Probit estimates based on data from 1973, 1974, 1976, 1977, 1980, 1982, 1984, 1985, 1987-91, 1993, and evennumbered years from 1994-2010. A quadratic in age, years of schooling, own income and indicators of gender and the year of the survey are included, and the estimation uses sampling weights.

***Ordered probit estimates based on data from 2002 and 2006. A quadratic in age, years of schooling, own income and indicators of gender and the year of the survey are included, and the estimation uses sampling weights. 


\section{Appendix Table A2. Parameter Estimates, Racial/Ethnic Effects on Stress (with non-Hispanic Whites as the Base Group)*}

\section{African-American}

Data Set and Dep. Var.:

\section{MEN WOMEN}

PSID 2003, Married*

$-0.0597 \quad-0.1039$

Probit on indicator

$(0.0354) \quad(0.0271)$

always/often stressed

$\mathrm{N}=$

1,649

2,189

\section{African- Non-black Asian-

American Hispanic American Other

ATUS 2010, 2012**

Ordered probit, stressed during

$-0.0037$

$-0.0132$

0.1574

activity, 6 to 0 scale

$(0.0513) \quad(0.0436)$

$(0.1288)$

$(0.0847)$

$\mathrm{N}=40,817$

*Includes each spouse's earnings, hours of work and health status, and family income and the ages and numbers of children.

**Includes all respondents who answered these questions in 2010 and 2012, The specification contains the same controls as the equations reported in the third rows of Table 2, a vector of the 18 major categories of time use indicating time spent on each major activity during the diary day, plus an indicator of gender and its interaction with marital status. Standard errors errors are clustered on the individual respondents. 